\section{Japan sets sights on success in nanotechnology}

A $s$ the United States launches its drive to capitalize on nanotechnology's potential, Japan is also gearing up for expansion in the field. Extra money has been earmarked for a host of new multidisciplinary programmes, centres and institutes for nanoscience. All of which is good news for researchers looking for work in the country.

But with expansion comes the possibility of organizational disarray. Some researchers describe Japan's current nanoscience programmes as chaotic. So the multitude of new programmes and institutes threatens to add to the madness as well as to the opportunity. By the end of the year, a high-level committee under the Council for Science and Technology will set out proposals covering how the various programmes should be coordinated.

It could be a mammoth task. The reorganized National Institute of Advanced Industrial Science and Technology (AIST), for example, will have six centres and four institutes spread around the country, all taking a

\section{f you have a clear \\ idea of what you want} to do in your research, you can get almost anything. multidisciplinary approach to nanoscience and nanotechnology. The Correlated Electron Research Center will explore new electronic materials for developing atom-based technology. For example, it will address questions of how to make quantum nanostructures and device junctions using oxide materials. "The physics of these exploratory electronic materials is not yet established," says director Yoshinori Tokura.

About 40 scientists will staff the centre, half of whom will be postdocs. Masataka Hirose of Hiroshima University will run AIST's Advanced Semiconductor Research Center, with significant cooperation from the private sector and universities. The centre will address fundamental problems in making semiconductors smaller than is possible using existing chip technology. It aims to reduce integrated circuit technology to 50-70 nanometres by 2007 .

\section{Plans for the future}

The National Institute for Materials Sciences (NIMS), to be formed from a merger of two Science and Technology Agency institutes, will undertake a range of research on materials that could be used for nanodevices and nanoscale environmental energy projects. Three likely areas of research, according to NIMS director Kazuhiro Yoshihara, are laser generation using quantum dots on semiconductors, single-electron transistors, and computers using

\title{
Land of opportunity
}

Permanent positions for foreigners are still exceedingly rare in Japan. But British-born, 0xford-trained Suzi Jarvis is one who has turned a string of grants into a six-year stay. Starting next year, she will become one of the few foreign researchers in the country to run their own lab. She will be based in Tsukuba at what is provisionally called the Nanotechnology Laboratory.

One of Japan's key attractions for foreign researchers is its tremendously well-equipped laboratories. Jarvis is working on nanoscale interactions and has an ultra-high vacuum and a liquid atomic-force microscope more or less to herself - a luxury almost unknown in other labs around the world. "If you have a clear idea of what you want to do in your research, you can get almost anything you want in terms of materials and instruments," she says.

"I've never had such freedom and resources," agrees Jose A. Torres, who researches the structural and conduction properties of gold nanowires, and has worked at several European research institutes. Indeed, Japanese researchers who travel abroad are shocked at the sparseness of some of the top US university labs.

The abundance and generosity of research grants and positions in Japan are also a draw. Salaries for postdoc researchers at the Agency of Industrial Science and Technology usually range between $¥ 6$ million and $¥ 8$ million (US\$54,000-72,500). And according to Jarvis, postdoctoral grants from the New Energy and Industrial Technology Development Organization pay about US $\$ 65,000$ a year - outdoing some professor's salaries in Britain - with a good deal of holiday and conference travel included.

Yet these grants are undersubscribed, and many directors of Japan's new institutes are already complaining of difficulties in getting well-trained international researchers to come to Japan. Part of the reason has to do with lack of awareness of opportunities in Japan, but there are also some cultural walls that stand in the way.

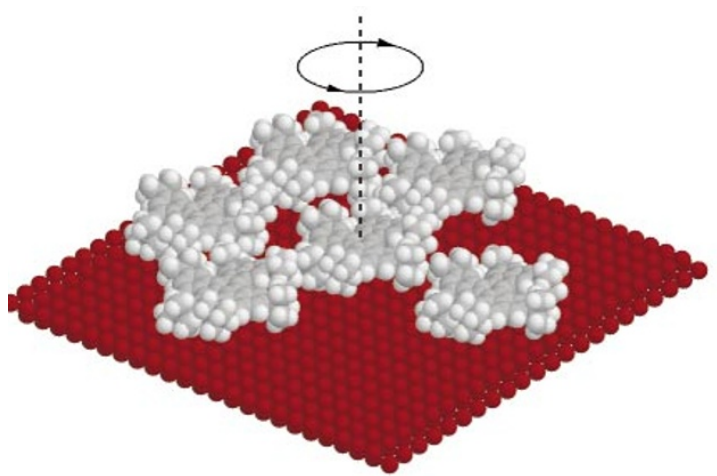

In a spin: nanotechnology could revolutionize many areas of science.

quantum dots or quantum wires. The institute will be housed in a new building and will have a yearly budget of $¥ 2.4$ billion (US\$22 million). Yoshihara expects the centre to employ around 100 people, of which about 60 will be taken from the predecessor institutions.

The New Energy and Industrial Technology Development Organization (NEDO) is supporting a separate nanomaterial programme. This is receiving yearly funds of $¥ 5$ billion for 5-7 years, which programme coleader Teruo Kishi hopes will be increased after next year. The programme will be split into eight projects, primarily representing different materials such as polymers and particles. Six project leaders will come from universities and two from the AIST. The project's 150-200 permanent staff will be joined by $100-200$ postdocs and temporary employees. Despite the fact that foreigners will probably not be candidates for the permanent positions, Kishi hopes to attract many postdocs from abroad.

University-led nanotech programmes appear poised to flourish as well. For example, Tadahiro Ohmi at Tohoku University aims to reduce quantum noise and statistical fluctuation as integrated circuits approach 50 nanometres and then move on towards 10 nanometres. The 50-nanometre level is already heavily supported with funds and researchers from industry, but Ohmi is looking for partners to move beyond that. Although it is hard to get funding for postdocs at a university, he is hoping to obtain greater industry support and so increase the number of postdocs on his project from two to ten within two or three years. There are also plans for a research institute focusing on future silicon technologies.

David Cyranoski is Nature's Japan correspondent.

Agency of Industrial Science and Technology (precursor to National Institute of Advanced Industrial Science and Technology)

\section{http://www.aist.go.jp}

New Energy and Industrial Technology Development Organization http://www.nedo.go.jp

National Research Institute for Metals (precursor to National Institute of Materials Sciences)

http://www.nrim.go.jp:8080/public/english 